Volume 1 | Issue 2

1991

\title{
Setting Health Care Priorities in Oregon
}

Michael J. Garland

Follow this and additional works at: https://scholarlycommons.law.case.edu/healthmatrix

Part of the Health Law and Policy Commons

\section{Recommended Citation}

Michael J. Garland, Setting Health Care Priorities in Oregon, 1 Health Matrix 139 (1991)

Available at: https://scholarlycommons.law.case.edu/healthmatrix/vol1/iss2/4

This Symposium is brought to you for free and open access by the Student Journals at Case Western Reserve University School of Law Scholarly Commons. It has been accepted for inclusion in Health Matrix: The Journal of Law-Medicine by an authorized administrator of Case Western Reserve University School of Law Scholarly Commons. 


\title{
SETTING HEALTH CARE PRIORITIES IN OREGON
}

\author{
Michael J. Garland, D. Sc. Rel. $\dagger$
}

\section{THE PROBLEM OF THE "UNINSURED"}

IN THE UNITED STATES some 31 million citizens (15\% of the population under 65) do not have health insurance. ${ }^{1}$ In Oregon, a state with a total population of 2.7 million, the number of uninsured persons has been determined to be approximately 400,000 , most of whom are employed full or part time. ${ }^{2}$ These facts are transformed into an ethical problem if health care is considered a common good and its distribution and financing matters of justice. The ethical challenge consists of finding a fair and compassionate way of responding to the fact that so many citizens are "uninsured for health care" at a time when health care costs are increasing at an unsustainable rate, when Medicaid programs are consistently straining their budgets and the usual patterns of employment based insurance are no longer serving to bring those "still left out" under the health insurance umbrella. The Oregon story is a microcosm of the national story.

The story originates in the closing years of the $1980 \mathrm{~s}$ and its conclusion, yet to be written, will extend well into the 1990s. In the decade of the eighties, expenditures for health care continued in the growth pattern of the previous decade and placed increasing strains on public and private programs we Americans use to finance health services through collective means (taxes and insurance). With this social mechanism we seek to alleviate for one another the

t Associate Professor of Public Health and Preventive Medicine and the Associate Director of the Center for Ethics in Health Care, Oregon Health Sciences University, cofounder and President of Oregon Health Decisions. Portions of this paper were originally published as Garland \& Hasnain, Health Care in Common: Setting Priorities in Oregon, HasTINGS CTR. REP. 16-18 (Sept. 1990).

1. P. Short, A. MonheIt, Y. K. BEAUREgARd, Uninsured AMERICANS: A 1987 Profile (1989) (report for Health Services Research and Health Care Technology Assessment, Department of Health and Human Services).

2. Oregon Office of Health Policy, Governors Commission on Health CARE, Report to Governor NeIl Goldschmidt on IMproving Access to Health CARE FOR AIL OREgonians, at 9 (1988). 
economic burdens of health care when illness and injury strike. But the social value of solidarity can get lost in the confusing particulars of different programs and institutions, each trying to meet their own goals and budgets.

Medicaid, the tax-based program focused on certain categories of poor and disabled members of society, places serious demands on the state's human services budget. In the absence of new tax dollars (a chronic condition of the past decade), Medicaid budgets in Oregon and throughout the nation have consistently strained their states' resources for human services. When meager discretionary funds fail to meet projected needs, or when desirable new programs require reallocation of resources, administrators and legislators have habitually used four ways of altering budget outlays: they redefine eligibility requirements to reduce (or increase) the number of persons served; they change the list of specific services included in the current benefit package; they vary the reimbursement rates for providers of services; they seek to improve productivity at a given level of expenditure. Except for productivity improvements, the other three strategies save dollars by making health care less accessible for the poor while increasing cost shifting, a hidden tax, to pay for limited continued access for the poor. Because productivity improvements are the hardest to accomplish and the slowest to show effect on a budget, the three access-reducing strategies are the most frequently used when administrators face budget shortfalls.

The Oregon story about responding to the uninsured is profoundly affected by fiscal constraints on Medicaid that have characterized the decade of the eighties. A significant feature of the Oregon story is the existence of Oregon Health Decisions (OHD), a community oriented organization dedicated to encouraging public involvement in ethical aspects of health policy. Since 1982, this organization has been conducting community awareness projects focused on ethical issues such as autonomy in the face of terminal illness and allocation of health care resources. In 1987 and 1988, OHD organized a series of community discussions on the question of general priorities for health care. ${ }^{3}$ State Senator John Kitzhaber, principal architect of the legislation to be discussed in this paper, chaired the Steering Committee for this project which held 19 meetings throughout the state and culminated with a "Citizen's Parliament" to focus the results of the community deliberations. The

3. Crawshaw, Garland, and Hines, Organ Transplants, a Search for Health Policy at the State Level, 150 W. J. MED. 361 (1988). 
product of the Parliament was a statement of fifteen principles "intended to be guideposts for the state legislature, insurance companies, and others concerned with health care resource allocation."4

Another significant element of Oregon's story is the 1987 legislative decision to finance an expansion of Medicaid eligibility for many persons living below the Federal Poverty Level, especially pregnant women, with dollars saved by not funding most organ transplants for Medicaid eligible persons. ${ }^{5}$ The tradeoff happened because both transplantation services and the "Poverty Level Medical Program" were optional programs available to states within federal Medicaid regulations.

The transplant issue became the center of a chaotic debate in Oregon and among many observers outside the state. The tragic case of a seven year old leukemia patient, whose family requested but was refused Medicaid assistance, became its symbolic focal point. Some objected violently to denying life-prolonging transplants to people just because they were poor. Despite the fact that private insurance policies marketed in the state were inconsistent about which, if any, transplants were covered, many advocates argued that the state Medicaid program was morally obliged to cover transplants on the grounds of equality. Others argued that certain health services, such as primary care for pregnant women, should be funded ahead of transplants-although there was no general list of priorities that would allow one to understand the reasons why any health services should come before any other.

The controversy revealed great ambiguity in public consciousness and made unmistakable the need for serious reform of the way Medicaid budget decisions are made. It also set the stage for thinking about how the state of Oregon might go about expanding third party coverage for persons currently uninsured for health care.

To make any progress toward universal third party coverage, whether in Oregon or at the national level, four component problems have to be worked on simultaneously. First, the strategy must aim at gaining effective access for all to adequate health care. Second, it must pay serious attention to controlling costs through delivery system reforms, administrative savings and efficiency in provider practices. Third, the plan must attend to maintaining quality of care. Fourth, it must be politically feasible, showing op-

4. Quality of Life in Allocating Health Care Resources, OREgon HeAlth Decisions, (Dec. 1988), at 1.

5. Rising Cost of Medical Treatment Forces Oregon to Play God, Washington Post, February 5, 1988, at A1, col. 1 . 
portunity for overcoming inertia, gaining interest group buy-in and having broad public acceptability.

Oregon's proposed solution is unique, but exhibits a general pattern also found in other state efforts to bring help to the uninsured: the state seeks to coordinate new developments in both Medicaid and private insurance in the effort to get all of the uninsured into some form of third party coverage.

\section{THE LEGISLATIVE PACKAGE}

The 1989 Oregon Legislature passed a package of three statutes intended to expand access to third party support for persons currently uninsured. One statute (Senate Bill $27^{6}$ ) expands Medicaid eligibility to $100 \%$ of the Federal Poverty Guideline; the second (Senate Bill 9357) sets up incentives for small businesses and their employees to purchase health insurance; and the third (Senate Bill $534^{8}$ ) provides requisite funding for a "high risk" insurance pool previously set up to help persons now considered "uninsurable" because of preexisting health conditions. These statutes will be referred to as "the Oregon Plan."

\section{SUMMARY OF SENATE BILL 27}

This law seeks to provide access to health services for persons with incomes at or below the Federal Poverty Level, to contain rising health services costs, to reduce cost shifting in the system and to promote the stability of the health care delivery system.

The basic provisions of Senate Bill 27 establish a program:

1. to provide Medicaid eligibility to all persons below the Federal Poverty Level;

2. to create a Health Services Commission (HSC) charged to prioritize services covered by Oregon Medicaid (with certain exemptions $^{9}$ );

6. S. Bill 27, (codified within OR. REv. STAT. $\$ \$ 414.025,414.036,414.042$ (1989)).

7. S. Bill 935, (codified within OR. REV. STAT. $\$ \S 316.096,317.113,353.725,353.765$, 353.775 (1989)).

8. S. Bill 534 , (codified within OR. REv. STAT. $\$ \$ 735.605-735.650$ (1989)).

9. Exemptions include: nursing facility services and home-based and communitybased services funded through the Senior Services Division; medical assistance for the aged, the blind and the disabled or medical care provided to children under current Oregon Law; institutional home-based and community-based Medicaid programs special to Oregon; Community Mental Health Program care for mentally retarded or developmentally disabled, or chronically mentally ill, or emotionally disturbed, and substance abuse treatment programs; services to children who are wards of the Children Services Division by order of the juvenile court, and health and mental health services to children and families provided through the division. 
3. to base priorities on comparative benefits of each service to the population being served;

4. to include with the priority report an estimate from an independent actuary stating the funding needed at each level to cover the costs of recommended services;

5. to conduct public hearings prior to submitting the report to the legislature;

6. to actively solicit public involvement in a community meeting process to build consensus on the values to be used to guide health resource allocation decisions.

7. to have the Joint Legislative Committee on Health Care determine whether or not to recommend the HSC report to the Legislative Assembly and to advise the Governor of its recommendation; and,

8. to leave to the Legislative Assembly the responsibility to fund the report to the extent that funds are available within the overall state budget. The legislature may not alter the priority list.

The Health Services Commission consists of 11 members appointed by the Governor to serve four year terms. The law requires that members of the HSC must include: 5 physicians (representing obstetrics, perinatal, pediatrics, adult medicine, geriatrics or public health, and including one Doctor of Osteopathy); 1 public health nurse; 1 social services worker; 4 consumers.

Waivers from certain requirements attached to the receipt of Federal Medicaid funding will be required for the implementation of new programs based on this law. The Oregon Medical Assistance Program (OMAP) is directed to seek such waivers after the Legislature has determined the Medicaid budget.

Prepaid managed care is proposed as the kind of health care system toward which OMAP is required to move under this law.

Whenever OMAP is required to reduce or permitted to expand its budget, the agency will eliminate or expand services in the order of priority established by the HSC. The population of eligible persons shall not be reduced, nor will the reimbursement rate in provider contracts be reduced.

Provider liability is safeguarded so that they shall not be subject to criminal prosecution, civil liability or professional disciplinary action for failing to provide a service which the Legislative Assembly has not funded or has eliminated from funding. Providers will be required, however, to advise a patient of any service, treatment or test that is medically necessary and would otherwise be provided but is not covered under the provider's contract with OMAP.

Mental health care and chemical dependency issues will be dealt 
with by having the HSC create a subcommittee charged to develop priorities for services to be presented by the HSC to the 1991 Legislative Assembly. These services are exempt from the first prioritization process.

\section{SUMMARY OF SENATE BILL 935}

The general purpose of the law is to extend access to health insurance to those with incomes above Federal Poverty but currently uninsured for health care.

Basic Provisions of the law establish a program:

1. to evaluate various alternatives for implementing a statewide insurance pool;

2. to assist small businesses (25 or fewer employees) to purchase health benefits;

3. to determine benefit packages to be offered by the insurance pool, based on a review of existing benefit plans and the recommendations of the Health Services Commission (HSC) established by Senate Bill 27;

4. to use the Medicaid package funded by the Legislature as the basic level for medical services that must be found in all Insurance Pool packages;

5. to establish guidelines for stepped increases in the proportion of the population covered by health insurance who were uninsured in 1989 ( 50,000 by October $1990 ; 100,000$ by 1991 ; and 150,000 by 1992$)$;

6. to use tax credits (for those employers who contribute to their employees' insurance premiums) to motivate voluntary employer participation in the program; and,

7. to levy a special additional payroll tax on employers who do not offer health insurance benefits by January 1, 1994.

The Insurance Pool Governing Board consists of seven members, six of whom are appointed by the Governor (including two employers and one representative of organized labor and two persons knowledgeable about insurance but who do not work in the insurance business) and one consumer representative appointed by the Director of the Department of Insurance and Finance.

The adequacy and effectiveness of health benefits in Insurance Pool packages and the effect of the plans on health care costs will be monitored by the Oregon Health Council, a sixteen member health policy advising council appointed by the Governor and representing the different geographic regions of the state.

\section{SUMMARY OF SENATE BILL 534}

This bill supplied needed funding to a High Risk Insurance Pool 
that had been created in the previous legislative session. Its basic provisions are:

1. provide coverage for those considered "uninsurable" in the market; and,

2. finance the pool by a combination of: state subsidy; assessment on insurers; and, premiums paid by subscribers or employers (with a ceiling set at $150 \%$ of standard premiums in the market).

\section{POLITICAL ASPECTS}

Senate President John Kitzhaber, the principal architect of the package, succeeded in gaining enough backing for the bills to win their passage. The essential motivating force behind the legislative success of the plan was the widespread belief that the system of dealing with Medicaid budgets needed to be reformed. The proposed instrument of reform was the prioritized list of services which could be used by the legislature and the agencies to guide the painful decisions of cutting back on the Medicaid budget or shifting resources from one category to another. This intuitive concept held the effort together throughout the legislative process.

The idea of the priority list was so central to this package that, in an innovative political move, Senator Kitzhaber convinced a private foundation to underwrite a demonstration project to give lawmakers an example of what the proposed priority setting process might yield. ${ }^{10}$ In the demonstration, four provider panels each prepared a prioritized list of services they typically offered (pregnancy, pediatrics, adult, and geriatric care). The four lists were then blended into a single list by an executive group. Finally, an actuarial consulting firm (Milliman and Robertson) estimated the costs of funding different levels on the priority continuum. The project report became part of the information available to lawmakers as they prepared to vote.

The demonstration was useful in helping resolve some legislators' doubts, but has subsequently confused several commentators who mistakenly presumed that the demonstration had permanent standing and authority. In fact, the HSC examined it briefly and then set it aside and went about creating its own methodology for producing a priority list.

As the HSC has carried on its work, the prioritization concept has continued to enjoy the political support of a coalition of interest

10. J. Golenski, Oregon Medicaid Prioritization Project, (demonstration project conducted by Medical Research Foundation of Oregon, Dec. 1988-Feb. 1989). 
groups such as consumer activists (the Oregon Health Action Campaign), organized labor (Oregon AFL/CIO), business (the Greater Portland Business Group on Health), and health providers (Oregon Medical Association, Oregon Hospital Association and Oregon Nurses Association). Each of these groups has a different primary reason for supporting the legislation, but the overlapping consensus remains functional. The process also maintains broad public acceptability due in large part to the openness and participatory nature of the HSC methodology. As in any real story, however, the outcome is never guaranteed either by the good will of the principal protagonists nor the general approval of less involved participants.

The continuing political development of the story will be profoundly affected by the impact of "Proposition Five," a property tax limitation passed by Oregon voters in November 1990. Proposition Five moves much of school funding from county property taxes to the state General Fund, putting tremendous strains on all state program budgets. Legislators in the 1991 Session were faced with a shifting revenue landscape while working out practical solutions to the challenges that threaten to overwhelm the Plan's goal of expanding access with equity and fairness.

\section{PRIORITIES AND ETHICAL CONCERNS}

The central moral premise of the Oregon Plan is the idea that, by using a prioritized list of health services to guide legislative budget decisions and agency administrative decisions, an ethically acceptable basic benefit package could be fashioned for Medicaid that would include those services considered most important and focus marginal decisions on services of lesser importance. The purpose of setting priorities is to define more rationally a basic benefit package for Medicaid and other third party programs directed toward the poor for whom the state has a primary responsibility.

Five areas of serious ethical concern have been raised by observers of the evolving Oregon Plan both inside and outside the state. First, because of its primary focus on Medicaid and the currently uninsured population, and because the legislative package makes no front end commitment of new dollars to pay for expanded access, the plan is at high risk of being grossly unfair to the poor, ${ }^{11}$ and, in particular, to women and children who are major recipients of

11. Tom Higgins, Oregon Plan Doesn't Merit a Medicaid Waiver," Healthweek, May 21, 1990, at 20. 
Medicaid support. ${ }^{12}$ This concern is heightened by the fact that the staging of the Oregon plan currently exempts from prioritization those Medicaid services now offered to the elderly, the blind and the disabled. ${ }^{13}$ At the heart of this criticism is the view that, if allocation or explicit rationing of health services is ever to be considered ethical, it must include everyone, rich and poor alike, in the rationing scheme. It is fundamentally unfair, they say, to expand access for poor persons by rationing care only among the poorest members of society, in effect asking only other poor persons to bear the burden of expanding access. ${ }^{14}$

This concern is a fundamental challenge faced by Oregon as a community, namely, how to achieve greater equity in the distribution of benefits and fairly distribute the burden of producing improved equity. These criticisms come from the world of theory and seek to illumine real policy choices. In some cases the theoretical frame of reference describes an ideal order - rationing to all members of the society is preferable to rationing only among the poor but the government now does not have the level of control over the whole range of third party systems needed to enact a universal rationing plan. On the other hand, the government does have control over health care systems aimed at providing access for the poor. Rationalizing that part of the system in pursuit of greater equity needs to be examined in terms of current policy dynamics and capacity to contribute to more ideal long term solutions.

Constructive ethical critique should explore whether proposed short term solutions are likely to contribute to or impede long term solutions to chronic problems. Fleck, for example, argues that persons now eligible for Medicaid would be making a rational choice to forego some lesser benefits in order to gain a greater assurance that they would have access to private health insurance even in low income employment circumstances-a situation they are likely to find themselves in as they move from Medicaid eligibility to greater financial independence. ${ }^{15}$ The Oregon Plan can thus be a defensibly just solution under present circumstances. $\mathrm{He}$ goes on to argue that

12. Children Defense Fund Reports, Poor Children and Women Targeted FOR Medicaid Reductions in OREgon, 1, 6-7 (Aug. 1990); Morrell, Oregon Puts Bold Health Plan on Ice, 259 ScI. 468-71 (1990); Budetti, Medicaid Rationing in Oregon: Political Wolf in a Philosopher's Sheepskin, 1 HeALTH MATRIX CASE W. RES. J. L. MED. 205, 216-17 (1991).

13. See supra summary of Oregon Senate Bill 27 p. 142.

14. Daniels, Is the Oregon Rationing Plan Fair?, 265 J. A.M.A. 2232 (1991).

15. Fleck, The Oregon Medicaid Experiment: Is It Just Enough?, 19 Bus. \& Prof. ETHICS J. 201 (1990). 
it would indeed be more just, if circumstances permitted, to include all, rich and poor alike, in one grand health care rationing scheme.

A basic error in some of the criticisms described above results from assuming that the Oregon Plan is unethical, not because it is rationing, but because it is rationing in circumstances that are not ideal. This makes for clear and forceful theoretical argumentation, but in the end only dimly illuminates the policy decisions that have to be made now in less than ideal circumstances. Medicaid budgets, for example, have to be dealt with both in the long term and the short term, and the problems of persons without health insurance who need health care now need to be attended to in the less than ideal circumstances of today.

A second concern raised by critical observers is that the plan may seriously corrupt community spirit by legitimizing a mean spirited attitude toward the poor. ${ }^{16}$ This criticism sees priority based allocations as ethically proper only if everyone in the community is at risk of having to live with the results of a priority system to be used to ration care. It is destructive of the moral basis of society to legitimize restrictions on health care for the poor while permitting the more well off to indulge in extravagant life styles, including excessive use of health services financed by collective resources such as private health insurance.

A third concern focuses on a subset of the community, namely health care providers, and urges that their basic ethic of patient advocacy will be corrupted if they play an active part in rationing health care. ${ }^{17}$ The Oregon plan, these critics argue, is a rationing scheme and health care providers should never get into the business of rationing care either at the bedside or at the statehouse.

A fourth concern asserts that the Oregon Plan, which requires considerable societal effort, amounts to a futile tinkering with a fundamentally defective system. ${ }^{18}$ For these critics the clear moral imperative is to get to a system of universal access to basic health care by the shortest possible path. Setting priorities is an intellectually and socially daunting exercise that merely postpones getting down

16. Caplan, How Can We Deny Health Care to Poor While Others Get Face Lifts? L.A. Times, April 25, 1989, at E6, col. 1.

17. R. Veatch, Deciding Levels of Care: The Case for Public Control (Oct. 1990) (unpublished manuscript presented at University of Minnesota Conference, "Drawing The Line: Defining a Basic Level of Health Care").

18. See Relman, The Trouble with Rationing, 323 NEw ENG. J. MED. 911 (1990); Himmelstein \& Woolhandler, A National Health Program for the United States, 320 NEW ENG. J. MED. 102 (1989); Himmelstein \& Woolhandler, Cost Without Benefit: Administrative Waste in U.S. Health Care, 314 NEW ENG. J. Med. 441 (1986). 
to real business on the primary challenge: making a commitment to every citizen and seriously rooting out wasteful administrative and technical practices in the health care delivery system.

A fifth moral concern is rooted in the technical difficulty of constructing a prioritized list of health services. Critics argue that health care services are too complex to be prioritized with scientific validity.$^{19}$ Outcome research is too slow and cumbersome to offer any hope for a scientifically based prioritization. Expert opinion ultimately may not be reliable because health care providers, the relevant experts, have a monetary interest in arranging for their typical services to score high on any prioritized list. On the other hand, information about how people value specific services in the abstract as opposed to when they actually need them, raises serious methodologic problems. How these values can be validly and accurately discovered and then related to technical information about outcomes for specific services is thought by some to be an insurmountable obstacle. These circumstances, it is urged, cast grave doubt on the prudence of attempting to base social policy on such questionable data and inference.

These criticisms are an important feature of the moral story. They should cause a profound wariness in those playing responsible parts in the unfolding Oregon experiment. All of the above concerns deserve careful scrutiny by members of the Oregon community who hope that the Oregon Plan will create a higher justice and more secure common good. The criticisms identify important issues for ongoing strategic corrections as the plan unfolds.

Each criticism should be met, not with theoretical arguments, but with decisions that can keep the Oregon Plan moving in an ethically acceptable direction. It is important to note that each critique is particularly relevant to different moments in the story or steps in the process (see Figure 1 below). Some of the critics, for example, have failed to grasp the phased nature of the process and take issue, not with what is actually going on, but with a collapsed conception of the Oregon Plan. The result is usually to assume that certain steps are finished before they have begun. A glaring example is the assumption that there was no political play left in the Plan regarding new dollars for Medicaid, when, in fact, that issue did not become fully activated until the HSC delivered the priority list to the legislature (in May of 1991). The relationship of specific critical is-

19. Schwartz \& Aaron, The Achilles Heel of Health Care Rationing, N.Y. Times, July 9, 1990, at F1, col. 1 . 
sues to steps in the prioritization process will be discussed below after the steps and their relationships with one another have been described.

\section{PRIORITY SETTING AS A FOUR STEP PROCESS}

The Oregon Plan creates a four step process for generating a list of health service priorities to be used as an instrument for budget decisions by the legislature and for program administration decisions by state agencies (See Figure 1). In the first step of the process,

Figure 1

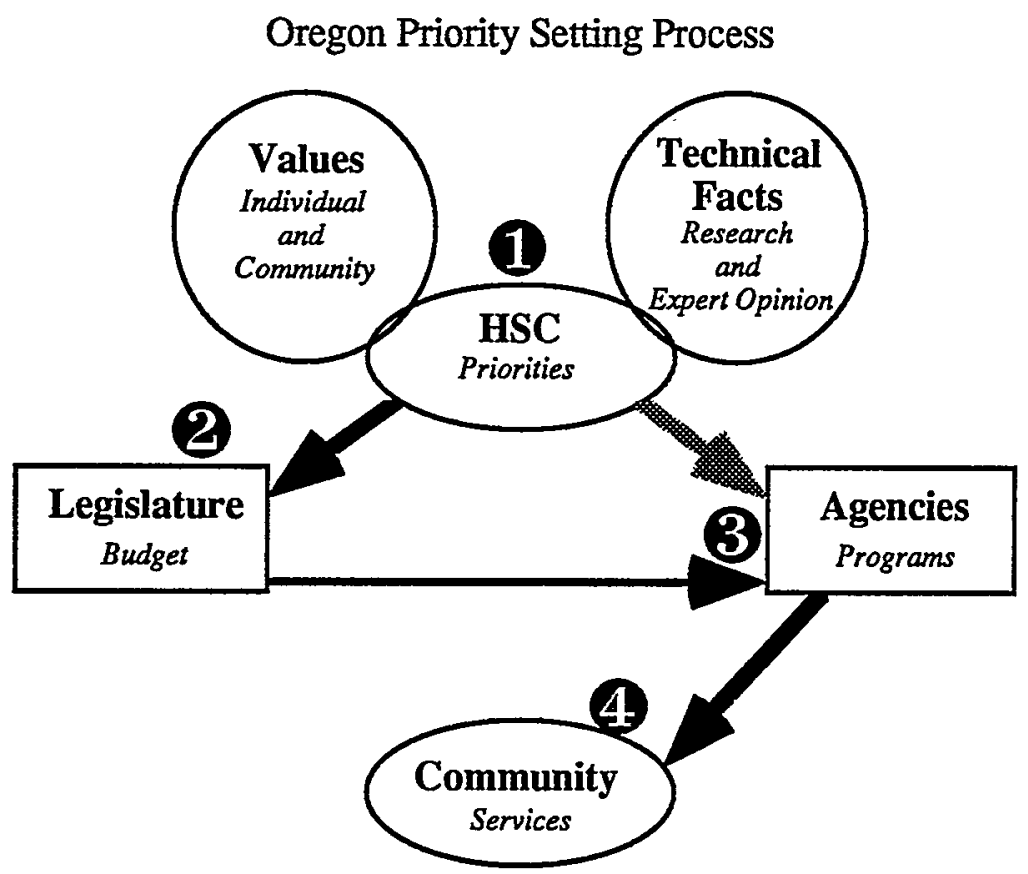

the Health Services Commission is required to develop a list of priorities based on community and individual values about health care and on technical information about the effectiveness of various health services relative to the needs of the population to be served. This list, together with actuarial estimates of the cost of funding different priority levels, is delivered to the Governor and the legislature in step two. The legislature's Joint Committee on Health Care must first consider the list and report its recommendations to both the Governor and the Legislative Assembly. Then the full legislature, using the list as a decision guide, has the task of setting budg- 
ets which will establish de facto the benefit package to be offered by Medicaid. This package will also become the basic minimum that must be contained in any private health insurance plan offered under the aegis of the small business (Senate Bill 935) and high risk (Senate Bill 534) insurance programs.

The third step in the process provides the relevant agencies (Medicaid, Oregon Medical Insurance Pool Board and High Risk Insurance Pool Governing Board) with the budget decision that creates the benefit package for Medicaid and associated private insurance packages. The first essential administrative task is for OMAP to request necessary waivers of several federal Medicaid regulations. Without approval from the Health Care Financing Administration (HCFA) in Washington, the Medicaid portion of the plan cannot be implemented. At this point the agencies must put in place all the administrative and evaluation elements that are necessary to run a complex social program. Figure 1 shows an arrow from the HSC to the agencies because part of the concept of the process is for the agencies to use the priority list to guide administrative decisions so that the new programs will be a consistent expression of the values on which the priorities are based.

The fourth step is the actual implementation of new service programs in the community. These services involve all persons at or below $100 \%$ of the Federal Poverty Level (e.g., an income of $\$ 880$ per month for a family of three) who will be declared eligible for Medicaid. Those with incomes above $100 \%$ Federal Poverty Level (unless already included in a special categorical program for Medicaid) will be served through either of the two health insurance pools.

\section{TIMELINE FOR THE PROCESS}

The timeline for these steps is expected to be as follows. Community values and technical information have already been gathered and the HSC has completed the priorities list (step 1) and will deliver the list (with actuarial estimates of the costs of funding different levels) to the legislature on May 1, 1991. Step 2, the legislative budget decision, is expected to be completed by mid summer 1991. The request for waivers (initial stage of step 3) will be submitted only after the budget decision has established the basic benefit package (late summer 1991). The waiver decision is expected to take six months, so that should waivers be granted by January 1992 , 
the new Medicaid program (step 4) would be implemented beginning in July 1992.

The process is temporally staged and cyclical. The HSC is a permanent Commission and is charged to review and revise the priority listing each biennium. For the 1993 legislative session, the HSC already has the task of bringing mental health and chemical dependency services into the priorities system, these two categories having been set aside from the first prioritization attempt.

The criticisms of the plan summarized above should be seen in relation to the several stages of the process. At step one, the priority generating stage, the issues of HSC methodology are paramount. The ethical challenge is to exercise wisdom in the selection of methods of gathering information and to maintain authenticity in combining value and technical information so as to produce a consistent list of priorities.

The Commission recruited 53 panels of provider experts to examine health conditions and associated treatments they commonly deal with. They were asked to describe probable outcomes of treating specific conditions in terms compatible with various states of well being. Data on preferences for certain states of well being were gathered from a random sample survey of Oregonians. This data and the outcome projections were combined in a net benefit formula used by the HSC to structure the priority list. In addition to the data on individual values about states of well being (the random sample survey data), the HSC, in collaboration with Oregon Health Decisions, developed a report on community oriented values about health care. Finally, the HSC held public hearings at seven sites throughout the state to give opportunity for special pleading by individuals and interest groups. All of these value information sources were being used by the HSC to shape the final priority listing that will go to the Legislature. Further information on the methodological questions and their results are available elsewhere. ${ }^{20}$

At step two the issues of justice and common good become paramount. Here the legislature must make policy judgments about the value of health care relative to other uses of public funds. The Legislature is always the primary locus of public policy efforts to do justice and promote the common good through public programs. Failures at this level in the past have produced the present circum-

20. The Oregon Health Services Commission. Prioritization of Health Services: A Report to THE Governor and Legislature (1991). See also, H.D. Klevit, Prioritization of Health Care Services, ARChIVES OF INTERNAL MED. 912 (1991). 
stance in which Medicaid programs nationally serve less than half of those persons below the Federal Poverty Level while some 15\% of the U.S. population remains without any form of third party coverage.

It is important for efforts at this step of the process to be critically examined in the light of ethical theory. But it is equally important for ethical theory to be critically examined in the light of real circumstances, needs and opportunities. A fundamental error made by several critics of the Oregon Plan is the assumption that there was no political play left in the process by the time the Legislature received the priority list. In fact, it is just that play that is required for justice and common good goals to be pursued and achieved, and the Oregon Plan is precisely designed for legislative choice to be determinative of the benefit package. The difference is that funding choices are to be made in terms of the priority list, not at random or arbitrarily or by jumping around an undifferentiated menu of services looking for just the right combination of program lines to achieve the bottom line needed to balance the budget.

Justice and common good issues continue to be primary at the third step the program design and implementation level for which state agencies have responsibility. The ethical issue of fidelity to the values and moral goals generated at the previous stages of the process is also essential here. The first element of the process at this stage will consist of applying for necessary Federal Medicaid waivers. It should be noted that the need for such waivers will certainly reach forward in time and affect the previous stage (step 2) i.e., the legislature's budget setting deliberations. It seems highly unlikely that the legislature will set the budget for Medicaid at a level doomed to be the basis of refusal of waivers needed to implement the Plan. The effort by the legislature to do justice at step two will, in part, be driven by the need to have a budget compatible with the sense of justice in the effective decision makers in Washington.

Some critics had prematurely begun lobbying the Health Care Financing Administration to reject the waiver request, but the decision they condemn had not yet been made. Advocates for organ transplantation coverage, for example, have made assumptions about how the priorities list would look before it had been created. On the other hand, advocates for child welfare, such as the Children's Defense Fund, which has declared itself unalterably opposed to a Medicaid waiver, made the assumption that there would be no new dollars added to the Medicaid budget before the legislature has had a chance to see the list and work with it as an instrument of 
budgetary decision making. These advocates were absolutely correct in their belief that the issue of new dollars was central to the question of justice in the Oregon Plan, but they mistakenly believed the question is closed before it had even been opened in earnest namely, when the legislature had the list in hand as an instrument of decision making. In fact the Oregon legislature budgeted significant new dollars to Medicaid in the 1991 session. These critics' commitment to advocacy is admirable, but their understanding of stages in the priority setting process is surprisingly deficient and the distortions they have introduced into the ethical debate may unintentionally prolong present injustices rather than alleviate them.

\section{REFLECTIONS ON COMMUNITY SOLIDARITY}

At the heart of the ethical problem the Oregon Plan seeks to address is the historical fact that our current system of solidarity for health care assigns some citizens the invidious status of outsiders. The history of the growth of third party coverage since World War II reveals a public policy tending toward universal entitlement but lacking in clear public commitment to the value of social solidarity on which such an entitlement logically rests. Between 1940 and 1950 , the proportion of the population with employment based hospital insurance rose from $9 \%$ to $57 \% .^{21}$ By the early seventies, after the passage of Medicare and Medicaid, the proportion of the population with some form of third party support for health care reached approximately $80 \%$ and has hovered around that point to the present. ${ }^{22}$ Those without insurance are simply left outside the circle of solidarity that the majority of us enjoy.

Michael Walzer in his analysis of the complex value pluralism of contemporary society offers instructive reflections on this point. He notes that the growth of communal provision of health care through both public and private third party systems gives a historical validation to the desire for health care, transforming the desire into a socially recognized need. ${ }^{23}$ Once desire is transformed into need, the distributional logic for health care should relate to illness, not wealth. In such a society, to be deprived of access to health care is a double loss. Those left out of third party solidarity experience the

21. O. W. ANderson, Health Services in the United States, A Growth ENTERPRISE SINCE $1875.134,142$ (1985).

22. Department of Health and Human Services, National Health InsurANCE RESOURCE BOOK, 86-91 (1974).

23. M. Walzer, Spheres of Justice, A Defense of Pluralism and Equality, 86-91 (1983). 
adverse consequences of having unmet health needs and they are told that they do not have standing as full fledged members of their society. They suffer both the misfortune of illness and the insult of exclusion.

In Walzer's analysis, this failure of community solidarity results from the misplaced use of personal wealth (being insured or being eligible for a welfare benefit) instead of illness as the criterion for the distribution of health care. It is reasonable to extend Walzer's thought and argue that this mistaken use of wealth as the basis for health care distribution is perpetuated by society's failure to achieve full consciousness of the degree of solidarity implicit in all third party financing arrangements. The community meeting process built into the Oregon Plan, and conducted for the HSC by Oregon Health Decisions, is an effort to counteract society's lack of attentiveness to the structure and consequences of an unfinished commitment to third party financing for health care. The structure of the meetings called for participants to adopt the language perspective of the first person plural and to identify values that reveal why health care is important to us as members of a community.

The community meeting process functions as a vehicle for participatory social criticism, namely, the articulation of moral discomfort because an important aspect of social life contradicts fundamental values a society espouses. The meetings facilitate group participation in the public examination of values declared by participants themselves to be of major importance for defining the moral meaning of health care. At the meetings the participants collaborate to "hold a mirror up" to themselves in which they can glimpse their authentic longings for higher values and face up to their own and - through themselves - society's moral inconsistencies, hypocrisies, and quiet accommodations with injustice.

These are the essential tasks of the social critic described by Michael Walzer ${ }^{24}$ in his study of that role as it is usually played by individual writers. Observations of the unfolding Oregon story make it evident that members of the community can, through the shared perspective of group dialogue, play a role analogous to Walzer's conception of the individual social critic. The community meetings opened up that role to ordinary people who participated in the process. Each participant in the context of group discussion be-

24. M. Walzer, The Company of Critics: Social Criticism and Political Commitment IN tHe TWentieth Century, 229-240 (1988). 
came a collaborator in the creation of a community owned and produced form of social criticism.

This participatory form of criticism fulfills Walzer's belief that the effective social critic must be psychologically "inside" the community being criticized, must feel connected to its successes and failures, must care passionately about the community's moral wellbeing, and remain attentive to the actually existing consciousness of the community. The capacity to generate this kind of participatory social criticism is essential to the exercise of meaningful community responsibility for the institution of health care at this point in its evolution when the unfinished agenda of universal access must be pursued with simultaneous concern for cost containment and rational allocation of resources.

Many critics of the Oregon plan have raised important moral concerns vital to the proper working out of the ethical story. Their contribution is extremely valuable. The critiques, however, of those who only view the story from the outside and point accusing fingers at "those people in Oregon" finally lack moral authenticity. They do not take responsibility for offering a better plan that can move the ethical agenda forward in a community to which they belong, in whose failures they are shamed and in whose good work they can take pride. These critics do not hold themselves accountable for the failure of their community to reach out in solidarity to those now uninsured for health care. Their criticisms provide the useful but limited benefit of a message from someone who looks on from a higher, but finally, too remote vantage point.

As the unfolding Oregon story continues and leaders at the state and national level struggle to extend the circle of solidarity and compassion to all citizens, the extent of direct community involvement in community forums will be critical. The health care system is now unfair in many ways. It also falls well short of an achievable level of common good. The possibility of change for the better is a challenge to the living ethics of the Oregon community-and the national community. On this point the unfolding Oregon story shows that we can reach a higher level of community responsibility for the fairness, prudence and common welfare generated by the health care system. The story also shows that improvements in fairness, prudence and common good are not guaranteed. They are always to be achieved. 